\title{
ANTICORPOS ANTIFOSFOLÍPIDES EM 66 PACIENTES COM INFARTO CEREBRAL ENTRE 15 E 40 ANOS
}

\author{
JOSÉ IBIAPINA SIQUEIRA NETO*, ANTONIO C. SANTOS**, \\ SORAIA R, CABETTE FÁBIO***, AMÉRICO C. SAKAMOTO****
}

\begin{abstract}
RESUMO - Os anticorpos antifosfolípides (aFLs) constituem grupo heterogêneo de imunoglobulinas que tem sido relacionado com alteraçōes na coagulabilidade. Indivíduos com títulos elevados teriam maior probabilidade de desenvolver tromboses de repetição, tanto arterial como venosa, e por conseguinte infarto cerebral (IC). Os testes para deteç̧ão mais utilizados em estudos clínicos são o inibidor lúpico e a anticardiolipina. Têm-se relatado maiores percentuais de positividade nesses testes em pacientes jovens com IC. Neste estudo procuramos investigar a prevalência desses anticorpos em pacientes com IC entre 15 e 40 anos em nosso Serviço. Examinamos 66 pacientes para presença de aFLs e obtivemos $16,65 \%$ de resultados positivos. Confirmamos diagnóstico de síndrome do anticorpo antifosfolípide primária em três $(4,55 \%)$ casos. Concluímos que a pesquisa de rotina para aFLs em pacientes jovens com IC está indicada neste grupo de pacientes, mas correlacioná-los com o episరdio isquêmico nem sempre é possível.
\end{abstract}

PALAVRAS-CHAVE: infarto cerebral, anticorpos antifosfolipides, hipercoagulabilidade.

\section{Antiphospholipid antibodies in 66 patients with cerebral infarction between 15 and 40 years old}

ABSTRACT - The antiphospholipid antibodies (aPLs) are a heterogenous group of immunoglobulins that have been related with alterations in blood coagulability in recent years. Patients with elevated titers of these antibodies have a high probability to develop thrombotic events, including cerebral infarct (CI). The tests currently used to detect these antibodies are the lupus anticoagulant and ELISA for anticardiolipin antibodies which have a larger proportion of positivity among young patients with CI. In our study we tested 66 patients with cerebral infarcts whose ages ranged from 15 to 40 years for the presence of lupus anticoagulant and anticardiolipin antibodies. The results showed that eleven (16.65\%) patients were positive for aPLs and three (4.55\%) of them fulfilled the diagnostic criteria for primary antiphospholipid syndrome. These data point out to the importance of investigating aPLs in young patients with CI and its high prevalence in this group compared with healthy population.

KEY WORDS: antiphospholipid antibodies, cerebral infarcts, hypercoagulation states.

A importância de estados protrombóticos na etiologia dos infartos cerebrais (IC) em jovens encontra-se bem definida ${ }^{12-14}$. Os anticorpos antifosfolípides (aFLs), incluindo o inibidor lúpico (IL) e a anticardiolipina ( $\mathrm{aCL}$ ), constituem uma família heterogênea de imunoglobulinas que ocupa lugar de destaque entre as etiologias de IC causados por hipercoagulabilidade. Pacientes com títulos elevados destes anticorpos apresentam trombose de repetição, perdas fetais, trombocitopenia e várias síndromes neurológicas, sendo as manifestaçōes isquêmicas cerebrais as mais importantes. Poucas informações encontram-se disponíveis acerca da prevalência dos aFLs em indivíduos sãos ${ }^{12}$. Os dados disponíveis no nosso país são escassos e provêm de populações selecionadas de pacientes.

*M.D., Professor Adjunto Doutor do Departamento de Medicina Clínica da Universidade Federal do Ceará; **M.D., Professor Assistente de Neurorradiologia do Departamento de Clínica Médica da Faculdade de Medicina de Ribeiråo Preto (FMRP) da Universidade de São Paulo (USP); ***M.D., Médica Assistente do Departamento de Neurologia, Psiquiatria e Psicologia Médica da FMRP/USP; ****M.D., Professor Associado do Departamento de Neurologia, Psiquiatria e Psicologia Médica da FMRP/USP. Aceite; 13-maio-1996.

Dr. José Ibiapina Siqueira Neto - Av. Historiador Raimundo Girão 444/701 - 60165-050 Fortaleza CE - Brasil. 
Baseados nessas observações delineamos este estudo com objetivo de averiguar a prevalência de aFLs em uma população de pacientes jovens com infarto cerebral e estabelecer entre os "positivos" quais preenchem critérios diagnósticos da síndrome do anticorpo antifosfolípide primária (SaFLP).

\section{CASUÍSTICA E MÉTODO}

Realizamos testes para deteç̧̃̃o de aFLs em 66 pacientes com infarto cerebral entre 15 e 40 anos; 48 $(72,75 \%)$ destes fizeram tanto pesquisa de IL como de anticorpo aCL. Todos os pacientes foram submetidos a protocolo de investigação que incluiu, além das análises laboratoriais de rotina, os seguintes exames: ecodopplercardiograma transtorácico, ultra-sonografia de carótidas e tomografia computadorizada de crânio. Angiografia cerebral e dosagens de anticoagulantes naturais (proteínas C e S; antitrombina III) foram solicitados em pacientes com diagnóstico indeterminado após a aplicação do protocolo básico. Quarenta e um $(62,10 \%)$ pacientes foram submetidos a angiografia cerebral.

O diagnóstico laboratorial do IL, inibidor lúpico, em nosso Serviço foi confirmado pelo teste de inibição da tromboplastina tecidual (ITT), em pacientes com tempo de tromboplastina parcial ativado (TTPA) elevado. Determina-se neste ensaio de coagulação a relação Tp / Tc (tempo do paciente sobre tempo do controle). Se esta relação for igual ou superior a 1,3 presume-se a presença do IL. A pesquisa do anticorpo aCL foi realizada por método imunológico, utilizando-se a técnica de ELISA, com antígeno cardiolipina de coração bovino e imunoglobulina anti-humana (IgG e IgM) de carneiro [Sigma Chemical Co.: C-1649 (Lote 39F8350)]. Pormenores da padronização desta técnica no HCFMRP/USP foram publicados por Costa et al. ${ }^{11}$. Os resultados foram considerados positivos quando o índice de ligação específica do soro do paciente sobre o índice de referência da mistura normal ("pool" de 100 amostras) for maior ou igual a 5,0.

O diagnóstico da SaFLP, síndrome do anticorpo antifosfolípide primária, obedeceu critérios propostos por Hughes et al. ${ }^{19}$ que estabeleceram a presença de no mínimo uma manifestação clínica maior (abortos de repetição, trombose arterial ou venosa, trombocitopenia) e um teste laboratorial positivo para confirmação da hipótese.

\section{RESULTADDS}

Dos 66 pacientes examinados para deteç̧ão de aFLs, 11 (16,65\%) apresentaram resultado positivo em pelo menos um dos testes (Fig 1). Quinze pacientes apresentaram resultados inconclusivos (valores limítrofes).

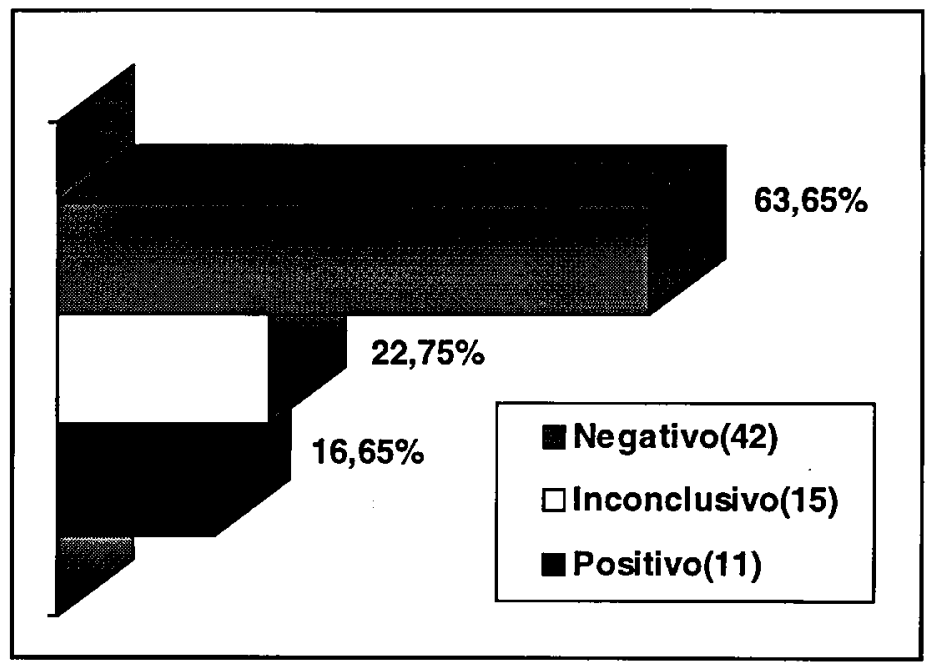

Fig l. Resultado da pesquisa de aFLs em 66 pacientes 
Tabela 1. Pacientes com resultado positivo na pesquisa de aFLs (11 casos)

\begin{tabular}{|c|c|c|c|c|}
\hline Paciente & $\begin{array}{l}\text { Idade no icto } \\
\text { (anos) }\end{array}$ & Positivo & Angiografia & Diagnóstico \\
\hline 1. ASR & 36 & $\mathbb{I L}$ & Normal & Lacunar \\
\hline 2. DM & 38 & $\mathbf{L}$ & Moyamoya & Moyamoya \\
\hline 3. NGS & 27 & $\mathrm{IL}+\mathrm{aCl}$ & $\mathbf{X X X}$ & LES* \\
\hline 4. MGDS & 40 & $\mathbb{L}$ & $\mathbf{X X X}$ & Lacunar \\
\hline 5. MLS & 25 & $\mathbf{L}$ & Trombose+Vasculite & SaFLP** \\
\hline 6. HAS & 36 & $\mathrm{aCL}$ & $\mathbf{X X X}$ & SaFLP** \\
\hline 7. MAM & 30 & $\mathrm{aCL}$ & Trombose & SaFLP** \\
\hline 8. GFV & 15 & acL & $\mathbf{X X X}$ & Poliarterite Nodosa \\
\hline 9. JRM & 37 & $\mathrm{aCL}$ & $\mathbf{X X X}$ & Cardioembólico \\
\hline 10. $\mathbf{R R}$ & 17 & acL & Arterite & LES* \\
\hline 11. WSS & 29 & $\mathrm{aCL}$ & Normal & Cardioembólico \\
\hline
\end{tabular}

*LES, Lúpus Eritematoso Sistêmico; **SaFLP, Síndrome do aFL Primária.

Dentre os 11 pacientes com resultados positivos na pesquisa de aFLs tivemos $3(4,55 \%)$ casos diagnosticados de SaFLP (Tabela 1). Os três pacientes eram do sexo feminino. A primeira paciente tinha amaurose, hipertensão severa e desenvolveu infarto fronto-parietal esquerdo com transformação hemorrágica. Apresentou IL positivo em várias amostras. A segunda tinha abortamento habitual, dispnéia aos esforços e relato de IC prévio por trombose da carótida interna esquerda. Evoluiu para óbito após novo icto e o resultado positivo do aCL só foi confirmado post-mortem. Na necropsia, além de infartos cerebrais antigos e recentes, apresentava cardiopatia isquêmica nãoaterosclerótica. A terceira paciente tinha hipertensão arterial leve e aCL positivo quando desenvolveu infarto cerebral parietal direito, sem outras queixas clínicas ou qualquer outro dado positivo após a aplicação do protocolo.

\section{DISCUSSÃO}

Os aFLs são um grupo heterogêneo de imunoglobulinas, incluindo o IL e a aCL, que estāo relacionadas a alterações da coagulação no sentido protrombótico ${ }^{14,25}$. Os mecanismos que proporcionam este aumento na coagulabilidade ainda não foram completamente esclarecidos. Ferro et al. ${ }^{13}$ relataram desordem no sistema fibrinolítico que seria provocada por elevação da atividade sérica do inibidor do plasminogênio ativado. Esta interferência na açāo do plasminogênio prejudicaria a fibrinólise e criaria condiçōes para o estado de hipercoagulabilidade.

Evidências acumuladas na última década confirmaram a associaçāo de tf́tulos elevados de aFLs com tromboses de repetição, abortamento habitual " neurologicas, sendo as "isquemias cerebrais" mais frequentemente relatadas ${ }^{8-10,12,17,18,22,24,27}$. As complicações neurológicas que mais se associam aos aFLs, além dos infartos cerebrais e isquemias oculares, são: demência, migrânia, coréia, mielite transversa, e síndrome de Guillain-Barré, dentre outros (como: epilepsia, amnésia global transitória) ${ }^{\mathbf{2} 22}$. Beynon \& Walport ${ }^{7}$ relataram maior incidência de lesões valvulares cardíacas em grupos de pacientes com lupus eritematoso sistêmico (LES) e altos títulos de aCL, mas o papel específico dos aFLs na patogênese de lesōes orovalvulares em populaçōes não selecionadas de indivíduos com altos títulos destas imunoglobulinas ainda permanece indeterminado. 
Quanto aos ensaios de coagulação empregados na deteç̧ão do inibidor lúpico, Tripplett ${ }^{23}$ relatou que o tempo de tromboplastina parcial ativado é o teste de "screening" mais apropriado. $\mathrm{Na}$ detecção do anticorpo anticardiolipina, através de método imunológico com técnica de ELISA, utiliza-se a padronização de Harris ${ }^{16}$.

O primeiro relato da associação de aFLs com infarto cerebral em pacientes jovens foi feito por Hart et al. ${ }^{17}$. Após este relato inicial uma grande série de publicaçōes tem fortalecido esta correlação ${ }^{18}$. Estudos de revisão relatam que os aFLs seriam um fator importante em $10 \%$ dos acidentes vasculares cerebrais ${ }^{2}$. Entretanto, Brey et al. ${ }^{9}$ detectaram títulos aumentados de aFLs em $46 \%$ de pacientes jovens com infarto cerebral e relatam ainda que este grupo tinha historia mais frequente de múltiplos eventos. Briley et al. ${ }^{10}$ já haviam previamente detectado o inverso, ou seja, $31 \%$ dos pacientes aFLs positivos tinham algum tipo de comprometimento neurológico (migrânia, demência e IC, entre outras). Na nossa série de 66 pacientes testados para detecção de aFLs, 11 (16,65\%) apresentaram positividade em pelo menos um exame ( $\mathrm{IL}$ ou $\mathrm{aCL}$ ). Estes resultados não foram tão espetaculares quanto os de Brey et al. ${ }^{9}$, mas são similares aos de Nencini et al. ${ }^{24}$ que encontraram $18 \%$. No nosso país, Tinone \& Scaff ${ }^{27}$ relataram $11,8 \%$ de testes positivos $\mathrm{em} 85$ pacientes com IC entre 14 e 45 anos. Nossos resultados sugerem "screening" de rotina para aFLs em pacientes jovens com IC, mesmo considerando a prevalência de $16,65 \%$ baixa se comparada a outros dados da literatura, porque resultados de estudos populacionais em indivíduos sãos com menos de 50 anos apontam prevalência de apenas 2 a $5 \%$.

Diagnosticamos síndrome do anticorpo antifosfolípide primária em três casos, ou seja, em 4,55\% dos testados. A literatura já documentou número suficiente de casos para nos garantir a utilizaçāo do termo síndrome do anticorpo antifosfolípide primária ${ }^{15,19}$. Pacientes com títulos elevados de aFLs associados a clínica de tromboses de repetição (arterial ou venosa), abortamento habitual e trombocitopenia, que não apresentam critérios suficientes para o diagnóstico de LES ou de outras colagenoses, passaram a receber diagnóstico de SaFLP. Entretanto, observa-se que apenas pequeno número de indivíduos com pesquisa para aFLs positiva seria alvo de perda fetal de repetição, de tromboses e de trombocitopenia. Logo, a presença de positividade nos testes para presença de aFLs não nos autoriza a fazer diagnóstico de SaFLP, se a clínica nāo for sugestiva. A aplicaçāo de critérios bem definidos no diagnóstico de SaFLP exige grande rigor para tornar possível comparar os resultados dos vários estudos ${ }^{1,15}$. Hughes et al. ${ }^{19}$ propuseram que seria necessário ao menos um aspecto clínico e um sorológico (8 semanas após a manifestação aguda) para o diagnóstico. O teste laboratorial deve ser repetido no mínimo mais uma vez para confirmação diagnostica. Utilizamos estes critérios para fazer o diagnóstico dos nossos casos, conforme descrito.

Tivemos ainda testes positivos em dois pacientes com LES e em outro com poliarterite nodosa. Harris et al. ${ }^{15}$ relataram que no LES tem-se encontrado 15 a $40 \%$ de casos com elevação dos títulos de aFLs. Asherson et al. ${ }^{5}$ relataram que nesses casos múltiplos infartos são comuns, seguidos de demência. Encontramos na literatura descrição de títulos aumentados de aFLs em pacientes com outras doenças do colágeno' ${ }^{12}$, mas não na poliarterite nodosa. Em 5 pacientes positivos para aFLs não conseguimos estabelecer relação de causa-efeito entre os anticorpos e o infarto. Dois eram hipertensos com infarto lacunar e outros dois apresentavam fontes potenciais de cardioembolia. $O$ últim̧o tinha diagnóstico de moyamoya.

Asherson \& Cervera ${ }^{4}$ descreveram uma série de lesōes cutâneas frequentemente encontradas na SaFLP que incluem: livedo reticular, tromboflebite, infarto cutâneo, gangrena digital, ulceraçōes, lupus discóide, papulose atrófica maligna, dentre outras. Ainda neste contexto teríamos a síndrome de Sneddon que é uma associação de livedo reticular generalizado e lesões cerebrovasculares obstrutivas. Esta doença evolui com episódios isquêmicos cerebrais sucessivos e a etiopatogenia é obscura. Vários autores estabeleceram correlação entre esta doença e a presença de aFLs so,77. Outros autores não confirmaram esta relação ${ }^{26,29}$. Não constatamos esta associacão na nossa série. 
Com relação aos achados angiográficos na SaFLP o "Antiphospholipid Antibodies in Stroke Study Group" (APASS) ${ }^{2}$ relatou alteraçōes em $49 \%$ dos exames, com maior parte dos estudos mostrando alterações trombóticas e apenas raramente lesões do tipo vasculite. Resultados recentes deste mesmo grupo ${ }^{3}$ confirmaram um risco aumentado para o primeiro evento também em pacientes idosos com títulos altos de aFLs, confrontando assim conclusões de trabalhos anteriores. Este grupo concluiu ainda que a associação dos aFLs com IC seria comparável à associação de IC com hipertensão arterial. Os resultados deste estudo enfatizam a necessidade de estudos prospectivos para estabelecer claramente a história natural de indivíduos com títulos altos de aFLs.

No que se refere ao tratamento, existe muita especulação quanto à eficácia de grande variedade de esquemas terapêuticos. Como consequência dos mecanismos de hipercoagulabilidade permanecerem parcialmente obscuros, existe espaço para utilização de esquemas com base meramente empirica ${ }^{6}$. Lockshin ${ }^{23}$ preconiza o uso de aspirina para doença de pequenos vasos, incluindo a doença cerebral difusa, e para oclusōes venosas menores. $O$ warfarin (cumarínico) é a droga de escolha para oclusões arteriais e obstruções venosas maiores. 0 mesmo autor ${ }^{23}$ comentou sobre o uso de corticosteróides e opta por empregá-los apenas nos casos com evidência clínica de LES ou com sintomas "Iupus-like".

Em resumo, nossos resultados mostram: [1] a pesquisa destes anticorpos deve ser obrigatória em todo paciente jovem com IC, mesmo porque já se encontra bem estabelecida a relação de aFLs com risco elevado de recorrência dos eventos tromboembólicos ${ }^{21}$, tornando fundamental o diagnóstico precoce para condutas profiláticas imediatas; [2] o percentual de positividade $(16,65 \%)$ encontrado foi significativo, se comparado a prevalência de aFLs na população geral ${ }^{12}$ mas ficou longe de reproduzir os $46 \%$ relatados por Brey et al. ${ }^{9}$; [3] a SaFLP é etiologia importante de IC em pacientes jovens $(4,55 \%)$ e devemos pensar nesta hipótese nos casos de trombose de repetição (múltiplos infartos), abortamento habitual, plaquetopenia, dentre outras manifestaçōes pouco usuais (cutâneas, demência) que se associem a IC.

\section{REFERÊNCIAS}

1. Alarcón-Segovia D, Sanchez-Guerrero J. Primary antiphospholipid syndrome. J Reumatol 1989:16:482-488.

2. Antiphospholipid Antibodies in Stroke Study Group (APASS). Clinical and laboratory findings in patients with antiphospholipid antibodies and cerebral ischemia. Stroke 1990;21:1268-1273.

3. Antiphospholipid Antibodies in Stroke Study Group (APASS). Clinical, radiological, and pathological aspects of cerebrovascular disease associated with antiphospholipid antibodies. Stroke 1993;24(Suppl.1):I120-I123.

4. Asherson RA, Cervera R. Antiphospholipid syndrome. J Invest Dermatol 1993;100(Suppl.1):S21-S27.

5. Asherson RA, Khamashta MA, Gil A, Vazquez J-J, Chan O, Baguley E, Hughes GRV. Cerebrovascular disease and antiphospholipid antibodies in systemic lupus erythematosus, lupus-like disease, and the primary antiphospholipid syndrome. Am J Med 1989;86:391-399.

6. Babikian VL, Levine SR. Therapeutic considerations for stroke patients with antiphospholipid antibodies. Stroke 1992;23(Supp1 I):133-137.

7. Beynon HLC, Walport MJ. Antiphospholipid antibodies and cardiovascular disease. Br Heart J 1992;67:281-284.

8. Brey RL, Gharavi AE, Lockshin MD. Neurologic complications of antiphospholipid antibodies. Rheum Dis Clin North Am 1993;19:833-850.

9. Brey RL, Hart RG, Sherman DG, Tegeler CH. Antiphospholipid antibodies and cerebral ischemia in young people. Neurology 1990:40:1190-1195.

10. Briley DP, Coull BM, Goodnight SH Jr. Neurological disease associated with antiphospholipid antibodies. Ann Neurol 1989;25:221-227.

11. Costa HLFF, De Moura MD. Ferriani RA, Anceschi MIS, Barbosa JE. Prevalence of anti-cardiolipin antiboby in habitual aborters. Gynecol Obstetr Invest 1993;36:221-225.

12. Coull BM, Levine SR, Brey RL. The role of antiphospholipid antibodies in stroke. Neurol Clin 1992;10:125-143.

13. Ferro D, Quintarelli C, Rasura M, Antonini G, Violi F. Lupus anticoagulant and the fibrinolytic system in young patients with stroke. Stroke 1993;24:368-370.

14. Greaves M. Coagulation abnormalities and cerebral infarction. J Neurol Neurosurg Psychiatry 1993;56:433-439.

15. Harris EG, Khamashta MA, Hughes GRV. Antiphospholipid antibody syndrome. In McCarty TJ (ed). Arthritis and allied conditions: a textbook of reumatology. Ed12. Philadelphia: Lea \& Febiger, 1993:1201-1212.

16. Harris EN. Serological detection of antiphospholipid antibodies. Stroke 1992;23(Suppl I):13-16.

17. Hart RG, Miller VT, Coull BM, Bril V. Cerebral infarction associated with lupus anticoagulants: preliminary report. Stroke 1984;15:114-118.

18. Hess D.C. Stroke associated with antiphospholipid antibodies. Stroke 1992;23(Suppl 1): 123-I28. 
19. Hughes GRV, Harris NN, Gharavi AE. The anticardiolipin syndrome. J Reumathol 1986;13:486-489.

20. Kalashinikova LA, Nasonov EL, Kushekbaeva AE, Gracheva LA. Anticardiolipin antibodies in Sneddon's syndrome. Neurology 1990;40:464-467.

21. Levine SR, Brey RL, Joseph CLM, Havstad S, on behalf of the Antiphospholipid Antibodies in Stroke Study Group. Risk of recurrent thromboembolic events in patients with focal cerebral ischemia and antiphospholipid antibodies. Stroke 1992;23(Suppl I):129-132.

22. Levine SR, Deegan MJ, Futrell N, Welch KMA. Cerebrovascular and neurologic disease associated with antiphospholipid antibodies: 48 cases. Neurology 1990;40:1181-1189.

23. Lockshin MD. Which patients with antiphospholipid antibody should be treated and how? Rheum Dis Clin North Am 1993;19:235-247.

24. Nencini P, Baruffi MC, Abbate R, Massai G, Amaducci L, Inzitari D. Lupus anticoagulant and anticardiolipin antibodies in young adults with cerebral ischemia. Stroke 1992;23:189-193.

25. Sammaritano LR, Gharavi AE, Lockshin MD. Anthiphospholipid antibody syndrome: immunologic and clinical aspects. Semin Arthrit Rheum 1990;20:81-96.

26. Stockhammer G, Felber SR, Zelger B, Sepp N, Birbamer GG, Fritsch PO, Aichner FT. Sneddon's syndrome: diagnosis by skin biopsy and MRI in 17 patients. Stroke 1993;24:685-690.

27. Tinone G, Scaff M. O papel dos anticorpos antifosfolípides nos acidentes vasculares cerebrais. Neurociencias 1994;2:3-7.

28. Tripplet DA. Coagulation assays for the lupus anticoagulant: review and critique of curent metodology. Stroke 1992;23(Suppl I):I11-I4.

29. Zelger B, Sepp N, Schmid KW, Hintner H, Klein G, Fritsch PO. Life history of cutaneous vascular lesions in Sreddon's syndrome. Hum Pathol 1992;23:668-675. 